\title{
Synthesis of both enantiomers of the docosahexaenoic ester of 13- hydroxyoctadecadienoic acid (13-DHAHLA)
}

\author{
Anders Vik ${ }^{\mathrm{a}^{*}}$, Trond Vidar Hansen ${ }^{\mathrm{a}}$ and Ondrej Kuda ${ }^{\mathrm{b}}$ \\ ${ }^{a}$ Department of Pharmacy, Section for Pharmaceutical Chemistry, University of Oslo, PO Box 1068 Blindern, N-0316, Oslo, Norway. \\ ${ }^{b}$ Institute of Physiology of the Czech Academy of Sciences, Videnska 1083, 14220, Prague, Czech Republic. \\ *Corresponding author: anders.vik@farmasi.uio.no
}

\begin{abstract}
Recently, several different classes of endogenous lipids have been reported that display antidiabetic and antiinflammatory effects. Due to their minute presence in human samples, access to synthetic material of each enantiomer becomes necessary for exact structural elucidation and extensive biological evaluation. Herein we report the multi-milligram synthesis of both enantiomers of the docosahexaenoic ester of 13hydroxyoctadecadienoic acid (13-DHAHLA) from commercially available starting materials.
\end{abstract}

Keywords:13-DHAHLA; 13-HODE; FAHFAs; Schwarz's reagent; Boland reduction.

\section{Introduction}

Fatty acid esters of hydroxy fatty acids (FAHFAs) are a new class of endogenous lipids that were first uncovered in adipose tissue, ${ }^{1}$ but has since been found in many other tissues, blood and breast milk. ${ }^{2}$ Elevated levels of FAHFAs have been associated with antidiabetic and anti-inflammatory effects. ${ }^{1}$ Very recently, the biological significance and strategies for the chemical syntheses of FAHFAs were reviewed. ${ }^{3}$ The FAHFAs can be categorized into subfamilies based on the composition of the fatty acid and hydroxy fatty acid, and regioisomers that differ in the position and configuration of the ester linkage connecting the two fatty acids. Most of the FAHFAs contain saturated lipid chains. Notably, in 2016 Kuda and co-workers identified omega-3 polyunsaturated fatty acid (PUFA) derived FAHFAs. ${ }^{4}$ One of these compounds contained docosahexaenoic acid (DHA) esterified to (9Z,11E)-13-hydroxyoctadeca-9,11-dienoic acid (13-HODE). This novel compound, which was termed 13DHAHLA, ${ }^{4,5}$ was uncovered from serum and white adipose tissue of both mice and diabetic patients supplemented with n-3 PUFAs. Interestingly, 13-DHAHLA displayed anti-inflammatory and pro-resolving properties. ${ }^{4}$ Moreover, in low micromolar concentration this novel FAHFA inhibited lipopolysaccharide-triggered activation of macrophages and human peripheral blood mononuclear cells, and enhanced phagocytic activity toward zymosan A particles. These experiments were performed with a racemic mixture of 13-DHAHLA. The total synthesis of each enantiomer is needed for further biological and pharmacological investigations. 


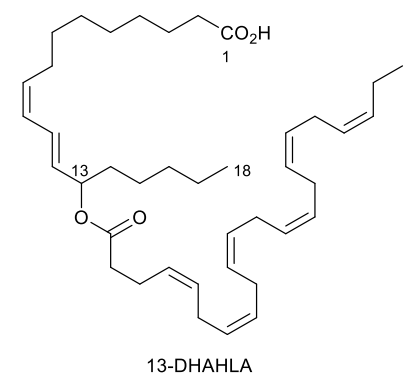

Figure 1. Structure of 13-DHAHLA.

\section{Synthesis}

The synthetic strategy for the synthesis of 13(S)-DHAHLA is depicted in Figure 2. The trimethylsilyletanoic ester in $\mathbf{1}$ was installed to allow for a selective hydrolysis of this group in the presence of an ester group on C-13 after a Steglich esterification of DHA with 1. Other key steps were a Sonogashira-cross coupling reaction between alkyne $\mathbf{2}$ and vinyl iodide $\mathbf{3}$, followed by a $Z$-selective alkyne reduction. Epoxide $\mathbf{4}$ was used in a reaction with Grignard reagent 5 for the synthesis of alkyne $\mathbf{6}$. Switching $\mathbf{4}$ for its enantiomer would give access to 13(R)-DHAHLA.

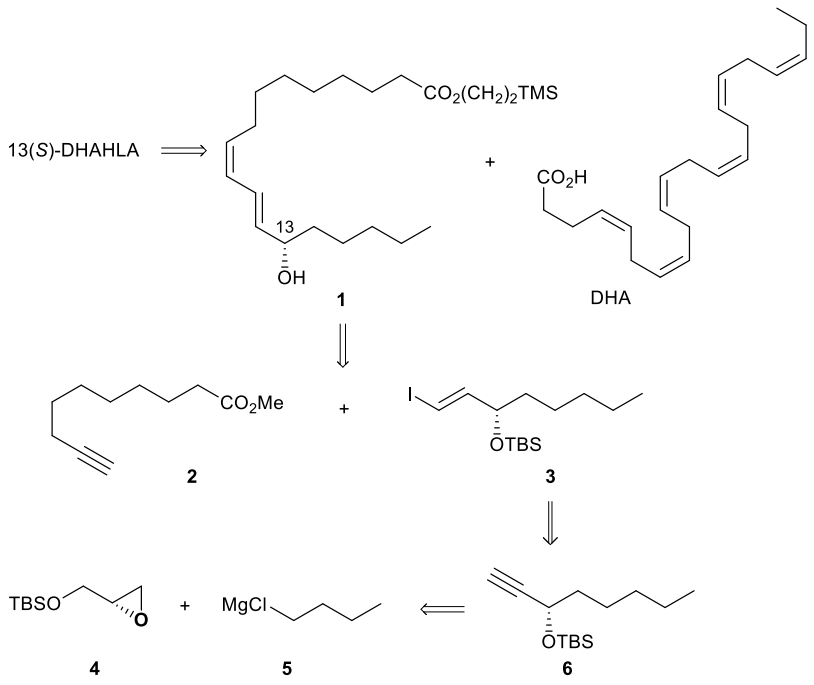

Figure 2. Retrosynthetic analysis of 13(S)-DHAHLA.

The synthesis of fragment 6 was achieved in $31 \%$ yield over six steps as outlined in Scheme 1. Commercially available $n$-butylmagnesium chloride (5) and a catalytic amount of $\mathrm{CuI}$ were added to tertbutyldimethylsilyl $(S)$-glycidyl ether (4) to afford the secondary alcohol 7 in $78 \%$ yield. Protection and selective removal of the primary silyl group using HF. pyridine gave the primary alcohol $\mathbf{8}$ in 59\% yield. Next, oxidation with Dess-Martin periodinane and a subsequent Corey-Fuchs reaction afforded alkyne $\mathbf{6}$ via vinyl dibromide 9 in 68\% yield over three steps. The alkyne ester 2 was prepared in two steps and 58\% yield from commercially available methyl 9-hydroxynonanoate (10), using a Dess-Martin oxidation and treating the resulting aldehyde with the Ohira-Bestmann reagent in methanol in the presence of $\mathrm{K}_{2} \mathrm{CO}_{3}$. 


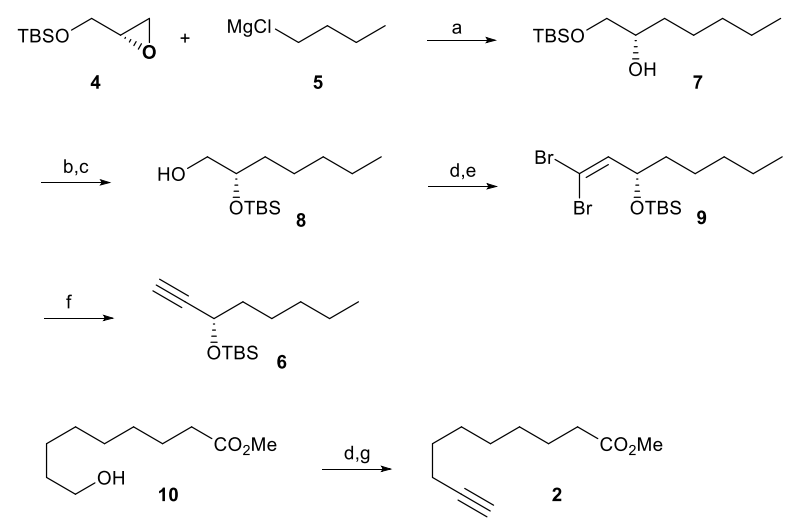

Scheme 1. Synthesis of fragments 6 and 2. Reagents and conditions: (a) CuI (0.1 equiv.), THF, $-50{ }^{\circ} \mathrm{C}-\mathrm{rt} ., 78 \%$; (b) TBSCl, imidazole, DMF; (c) HF. pyridine, THF, pyridine, $16 \mathrm{~h}$, overall yield for two steps 59\%; (d) Dess-Martin periodinane, $\mathrm{NaHCO}_{3}$, $\mathrm{CH}_{2} \mathrm{Cl}_{2}$; (e) $\mathrm{CBr}_{4}, \mathrm{PPh}_{3}, \mathrm{Zn}, \mathrm{CH}_{2} \mathrm{Cl}_{2}$, overall yield for two steps 70\%; (f) MeLi, THF, -78 ${ }^{\circ} \mathrm{C}$, 97\%; (g) Dimethyl(1-diazo-2oxo propyl)-phoshonate, $\mathrm{K}_{2} \mathrm{CO}_{3}, \mathrm{MeOH}$, overall yield for two steps $58 \%$.

We next applied a recently reported method for an in situ formation of the Schwartz's reagent ${ }^{6}$ for the conversion of alkyne $\mathbf{6}$ into the vinyl iodide 3 . The labile vinyl iodide $\mathbf{3}$ was immediately reacted in a Sonogashira cross-coupling reaction with alkyne 2. Purification of the resulting product was not successful, but removal of its silyl group with TBAF provided pure alcohol 11 in 34\% yield over the four steps. Next, the conjugated alkyne in 11 was reduced stereoselectively using Boland's method ${ }^{7}$ in $88 \%$ yield. Hydrolysis of the ester group gave 13(S)HODE, which due to its biological properties has been the focus for numerous synthetic and chemo-enzymatic syntheses. ${ }^{8}$ The fluoride sensitive trimethylsilyl ethyl ester protecting group was installed on 13(S)-HODE to give alcohol 1. A Steglich esterification with DHA provided 13(S)-DHAHLA after removal of the trimethylsilyl ethyl ester with fluoride. The enantiomer, 13(R)-DHAHLA, was prepared from tert-butyldimethylsilyl $(R)$-glycidyl ether (ent-4) using the same protocol as described for 13(S)-DHAHLA. ${ }^{9}$

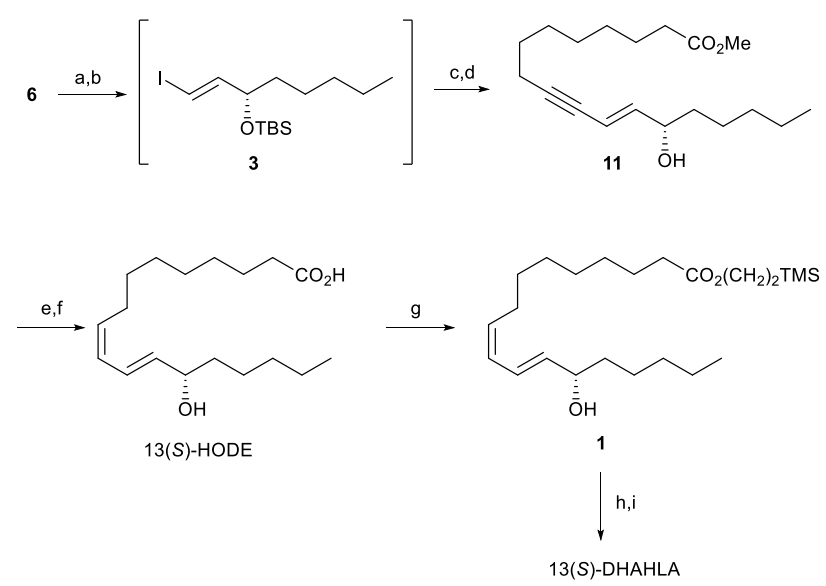

Scheme 2. Synthesis of 13(S)-DHAHLA. Reagents and conditions: (a) $\mathrm{Cp}_{2} \mathrm{ZrCl}_{2}$ (1.5 equiv.), $\mathrm{LiAlH}(\mathrm{O}-t \mathrm{Bu})_{3}$ (1.5 equiv.), THF; (b) $\mathrm{I}_{2}$ (1.5 equiv.) (c) 2, $\mathrm{Pd}\left(\mathrm{PPh}_{3}\right)_{4}$ (0.04 equiv.), CuI (0.05 equiv.), benzene, Et $2 \mathrm{NH}$; (d) TBAF, THF, $4{ }^{\circ} \mathrm{C}, 16$ h, $34 \%$ overall yield from 6; (e) $\mathrm{Zn}\left(\mathrm{Cu} / \mathrm{Ag}\right.$ ), $\mathrm{MeOH}, \mathrm{H}_{2} \mathrm{O}, 18 \mathrm{~h}, 88 \%$; (f) $\mathrm{LiOH}, \mathrm{MeOH}, \mathrm{THF}, \mathrm{H}_{2} \mathrm{O}, 80 \%$; (g) $\mathrm{TMSCH}_{2} \mathrm{CH}_{2} \mathrm{OH}, N, N^{\prime}-$ dicyclohexylcarbodiimide (1.2 equiv.), DMAP (0.5 equiv.), $\mathrm{CH}_{2} \mathrm{Cl}_{2}, 68 \%$; (h) $\mathrm{DHA} \quad\left(2.0\right.$ equiv.), $N, N^{\prime}-$ dicyclohexylcarbodiimide (2.5 equiv.), DMAP (0.75 equiv.), $\mathrm{CH}_{2} \mathrm{Cl}_{2}, 87 \%$; (i) TBAF, THF, rt., 2 h, $50 \%$. 


\section{Conclusions}

A stereoselective synthesis of 13(S)-DHAHLA has been achieved in $2 \%$ overall yield over 15 steps. Its enantiomer, 13(R)-DHAHLA, was synthesized from tert-butyldimethylsilyl $(R)$-glycidyl ether using the same sequence and in a similar yield. A recent and convenient protocol for making vinyl iodides was used. ${ }^{6}$ Matching of the synthetic compounds with endogenous material, and investigations of the biological effects of each enantiomer, are currently ongoing and will be reported elsewhere.

\section{Acknowledgements}

Funding from FRIPRO-FRINATEK 230470 from the Norwegian Research Council is gratefully appreciated.

\section{Supplementary material.}

Supplementary data to this article can be found online at https://

\section{References and notes}

1. Yore, M. M.; Syed, I.; Moraes-Vieira, P. M.; Zhang, T.; Herman, M. A.; Homan, E. A.; Patel, R. T.; Lee, J.; Chen, S.; Peroni, O. D.; Dhaneshwar, A. S.; Hammarstedt, A.; Smith, U.; McGraw, T. E.; Saghatelian, A.; Kahn, B. B. Cell 2014, 159, 318.

2. (a) Zhang, T.; Chen, S.; Syed, I.; Stahlman, M.; Kolar, M. J.; Homan, E. A.; Chu, Q.; Smith, U.; Boren, J.; Kahn, B. B.; Saghatelian, A. Nat. Protoc. 2016, 11, 747. (b) Brezinova, M.; Kuda, O.; Hansikova, J.; Rombaldova, M.; Balas, L.; Bardova, K.; Durand, T.; Rossmeisl, M.; Cerna, M.; Stranak, Z.; Kopecky, J. Biochim. Biophys. Acta, Mol. Cell Biol. Lipids 2018, 1863, 126-131 (c) Zhu, Q.-F.; Yan, J.-W.; Gao, Y.; Zhang, J.-W.; Yuan, B.-F.; Feng, Y.-Q. J. Chromatogr. B: Anal. Technol. Biomed. Life Sci. 2017, 1061-1062, 34-40.

3. Balas, L.; Feillet-Coudray, C.; Durand, T. Chem. -Eur. J. 2018, 24, 9463, and references cited therein.

4. Kuda, O.; Brezinova, M.; Rombaldova, M.; Slavikova, B.; Posta, M.; Beier, P.; Janovska, P.; Veleba, J.; Kopecky, J.; Kudova, E.; Pelikanova, T. Diabetes 2016, 65, 2850.

5. In the literature, $(9 Z, 11 E)$-13-hydroxyoctadeca-9,11-dienoic acid (13-HODE, also known as coriolic acid) is frequently also referred to as 13-hydroxy linoleic acid (13-HLA). Hence the name 13-DHAHLA, which has become the established name in the literature for the DHA ester of $(9 Z, 11 E)$-13-hydroxyoctadeca-9,11-dienoic acid.

6. Zhao, Y.; Snieckus, V. Org. Lett. 2014, 16, 390.

7. Boland, W.; Schroer, N.; Sieler, C.; Feigel, M. Helv. Chim. Acta 1987, 70, 1025. 
8. (a) Moustakis, C. A.; Weerasinghe, D. K.; Mosset, P.; Falck, J. R.; Mioskowski, C. Tetrahedron Lett. 1986, 27, 303. (b) Kobayashi, Y.; Okamoto, S.; Shimazaki, T.; Ochiai, Y.; Sato, F. Tetrahedron Lett. 1987, $28,3959$. (c) Chan, C.; Cox, P. B.; Roberts, S. M. J. Chem. Soc., Chem. Commun. 1988, 971. (d) De Montarby, L.; Mosset, P.; Gree, R.Tetrahedron Lett. 1988, 29, 3937. (e) Tranchepain, I.; Le Berre, F.; Dureault, A.; Le Merrer, Y.; Depezay, J. C.Tetrahedron 1989, 45, 2057. (f) Yadav, J. S.; Deshpande, P. K.; Sharma, G. V. M.Tetrahedron 1992, 48, 4465. (g) Babudri, F.; Fiandanese, V.; Marchese, G.; Punzi, A. Tetrahedron 2000, 56, 327, and references cited therein. (h) Kumari, A.; Gholap, S. P.; Fernandes, R. A. Chem. - Asian J. 2019, 14, 2278.

9. Spectroscopic data obtained for $13(S)$-DHAHLA: $[\alpha]_{D}^{25}=+1.4\left(c=0.5\right.$, hexane). UV (hexane) $\lambda_{\max } 235 .{ }^{1} \mathrm{H}$ NMR $\left(600 \mathrm{MHz}, \mathrm{CDCl}_{3}\right) \delta 6.50(\mathrm{dd}, J=15.3$ and $\left.11.1 \mathrm{~Hz}, 1 \mathrm{H}), 5.83(\mathrm{t}, J=11.1 \mathrm{~Hz}, 1 \mathrm{H}), \mathrm{dd}, J=15.1 \mathrm{and} 7.5 \mathrm{~Hz}, 1 \mathrm{H}\right)$, 5.51-5.27 (m, 14H), 2.90-2.77 (m, 10H), 2.43-2.32 (m, 6H), 2.22-2.12 (m, 2H), 2.12-2.02 (2H), 1.70-1.54 (m, 2H), 1.69-1.54 (m, 4H), 1.37-1.25 (m, 14H), $0.97(\mathrm{t}, J=7.5 \mathrm{H}, 3 \mathrm{H}), 0.88(\mathrm{~m}, 3 \mathrm{H}) .{ }^{13} \mathrm{C} \mathrm{NMR}\left(150 \mathrm{MHz}, \mathrm{CDCl}_{3}\right) \delta$ $178.5,172.7,133.8,132.2,131.1,129.3,128.7,128.4,128.4,128.3,128.3$ (2xC), 128.2, 128.2, 128.2, 128.0, $127.7,127.2,75.1,34.7,34.7,33.9,31.7,29.9,29.5,29.1,29.1,29.0,27.9,25.8$ (2xC), 25.8, 25.7, 25.0, 24.8, 23.0, 22.7, 20.7, 14.4 and 14.2. HRESITOFMS: $m / z$ 629.4540 $[M+\mathrm{Na}]^{+}$(calcd for $\mathrm{C}_{40} \mathrm{H}_{62} \mathrm{NaO}_{4}, 629.4540$ ). Spectroscopic data obtained for 13(R)-DHAHLA: $[\alpha]_{D}^{25}=-1.2(c=0.5$, hexane). All other spectroscopic data of 13(R)-DHAHLA were identical to that of its enantiomer, 13(S)-DHAHLA. 